\title{
PROPOSAL PROGRAM KREATIVITAS MAHASISWA PEMBUATAN FLUME TANK SEDERHANA UNTUK PRAKTIKUM HIDRAULIKA DI FAKULTAS TEKNIK UNIVERSITAS IBN KHALDUN BOGOR
}

\author{
Muhammad Khaerul Insan, Muhammad Ikhsan, Tirta Adhyaksa. \\ banceto@gmail.com \\ Mahasiswa Fakultas Teknik
}

\begin{abstract}
ABSTRAK
Flume tank atau tanki berarus adalah sebuah bentuk konstruksi alat yang dapat menampung air dalam jumlah tertentu dan dapat digunakan sebagai alat pengamatan, pengukuran maupun pengujian yang dilengkapi dengan arus air yang terkontrol. Pada proses perkuliahan hidrolika saluran terbuka dalam suatu instansi pendidikan tinggi perlu suatu media pembelajaran sebagai aplikasi teori yang dijelaskan pada materi perkuliahan, terkadang pada proses praktikum diperlukan kunjungan ke pihak yang bersedia dan memiliki alat praktikum yang akan digunakan sebagai media pembelajaran. Maka dari itu, penelitian ini bertujuan untuk membuat inovasi terbaru terhadap Flume Tank yang pada umumnya digunakan pada proses praktikum pembelajaran hidrolika saluran terbuka agar menjadikannya lebih praktis dan efisien di Fakultas Teknik Jurusan Teknik Sipil Universitas Ibn Khaldun Bogor.
\end{abstract}

Kata Kunci: Flume Tank, Praktikum Hidrolika, Media Pembelajaran.

\section{PENDAHULUAN}

\section{Latar Belakang}

Pada proses perkuliahan hidrolika saluran terbuka dalam suatu instansi pendidikan tinggi perlu suatu media pembelajaran sebagai aplikasi teori yang dijelaskan pada materi perkuliahan, terkadang pada proses praktikum diperlukan kunjungan ke pihak yang bersedia dan memiliki alat praktikum yang akan digunakan sebagai media pembelajaran. Namun umumnya untuk media pembelajaran terdapat kurangnya perkembangan terhadap kemajuan alat terbaru, sehingga proses pemahaman terhadap materi pembelajaran sedikit terhambat oleh keterbatasan sarana.
Dalam hal ini, rencana perancangan inovasi terutama pada permodelan Flume Tank yang digunakan pada umumnya, akan ditambahkan beberapa alat penguji untuk mempermudah pengguna praktikum dalam segi, tahan lama, perawatan mudah, praktis dan efesien. Alat pengukuran dan pengujian tambahan pada permodelan Flume Tank ini akan mendapat nilai manfaat lebih dari hasil uji, antara lain:

a. Pengukuran Debit air pada Flume Tank

b. Pengukuran terhadap Hydrolic Jump

c. Pengujian Parshall Flume (sub-kritis, kritis dan superkritis)

d. Pengukuran debit air setelah Parshall Flume 
Maka dari itu, penelitian ini bertujuan untuk membuat inovasi terbaru terhadap Flume Tank yang pada umumnya digunakan pada proses praktikum pembelajaran hidrolika saluran terbuka agar menjadikannya lebih praktis dan efisien di Fakultas Teknik Jurusan Teknik Sipil Universitas Ibn Khaldun Bogor.

\section{Flume Tank}

Flume tank atau tanki berarus adalah sebuah bentuk konstruksi alat yang dapat menampung air dalam jumlah tertentu dan dapat digunakan sebagai alat pengamatan, pengukuran maupun pengujian yang dilengkapi dengan arus air yang terkontrol (Arnold, 1969). Flume tank pada umumnya digunakan untuk pengamatan oseanografi, fisika fluida, biologi air, mensimulasikan tingkah laku ikan dan bentuk kapal (performa kapal) dan lain-lain.

Namun tidak hanya itu, Flume Tank dapat juga digunakan untuk penelitian mengenai tingkah laku air. Untuk menentukan koefisien debit pada Flume dengan menggunakan bendung baik secara skala maupun skalatis digunakan. (Sutyas Aji, Yanus T, dan Martiani, 2014:26-27).

\section{Bendung}

Bendung selain digunakan sebagai peninggi elevasi muka air, juga digunakan sebagai pengukuran debit air dan Hydrolic Jump. Bendung dan bendungan masing-masing memiliki fungsi berbeda, Bendung dibuat sebagai peninggi elevasi muka air sehingga dengan kondisi permukaan air yang telah dibendung air akan dialirkan ke tempat yang kita inginkan.Sedangkan bendungan digunakan untuk menampung aliran, bila terjadi over flow diharapkan tidak terjadi banjir besar yang diakibatkan terlalu tingginya elevasi permukaan air yang mengalir pada saluran tersebut, atau dengan kata lain fungsi daripada bendungan sebagai pengendali air (Sartono, 2014:4).

\section{Hydrolic Jump}

Hydrolic Jump adalah loncatan air akibat perbedaan ketinggian saluran terbuka, pada hal ini dalam pengamatan terdapat lengkungan pada aliran di permukaan air pada saluran tersebut. Pada saluran persegi panjang mendatar untuk aliran superkritis, energi ini akan mengalir kencang dimana bilangan Froude $>1$, karna pada posisi aliran ini akan menimbulkan gerusan pada saluran. Aliran kritis adalah keadaan aliran dimana energi yang di alirkan dalam posisi tenang, spesifiknya untuk suatu debit tertentu adalah minimum atau bilangan Froude $=1$. Aliran sub-Kritis adalah dimana aliran dikatakan berbeda dalam keadaan kritis, dimana energi pada Froude $<1$ pada keadaan ini peran gaya tarik bumi sangat menonjol karena memiliki kecepatan rendah dan sering dikatakan tenang. (E.V Nensi Rosalina, 1984).

\section{Parshall Flume}

Parshall Flume adalah teradapat berbagai debit yang berbeda dikarenakan perbedaan ukuran saluran yang berpengaruh terhadap arus aliran dan hambatan permukaan, dan media permukaan basah DAS (Daerah Aliran Sungai) itu sendiri (Asikin Muchtar dan Nurdin Abdullah 2007). 


\section{METODE PENGABDIAN}

Dalam penelitian ini, metode yang digunakan berupa pengumpulan data Flume tank yang sudah banyak digunakan oleh instansi lain. Karena akan dilakukan inovasi terhadap flume tank, maka perlu dilakukan pembandingan antara flume tank yang akan di inovasi dengan flume tank yang sudah ada.

Setelah dilakukan perbandingan, maka akan diketahui kekurangankekurangan dari flume tank yang sudah ada, sehingga dapat dilakukan sebuah inovasi dari flume tank tersebut. Selanjutnya, akan dilakukan perhitungan untuk dimensi flume tank yang akan dibuat agar sesuai dengan dimensi standar yang telah ditentukan.
Selanjutnya, dapat dilakukan kalibrasi alat uji yang telah dibuat dengan cara mengukur hasil pada alat yang telah diproduksi dan membandingkannya dengan perhitungan manual sesuai rumus per materi pengujian. Apabila hasil pada alat telah sesuai dengan hasil pada perhitungan manual, maka alat tersebut telah terkalibrasi dengan baik dan dapat digunakan untuk keperluan praktikum di Laboratorium Hidrolika Fakultas Teknik Universitas Ibn Khaldun Bogor.

Untuk alur metode penelitian yang akan digunakan dapat dilihat pada diagram alir yang akan dijelaskan pada sekma berikut ini. 


\section{Diagram Alur Metode Penelitian}

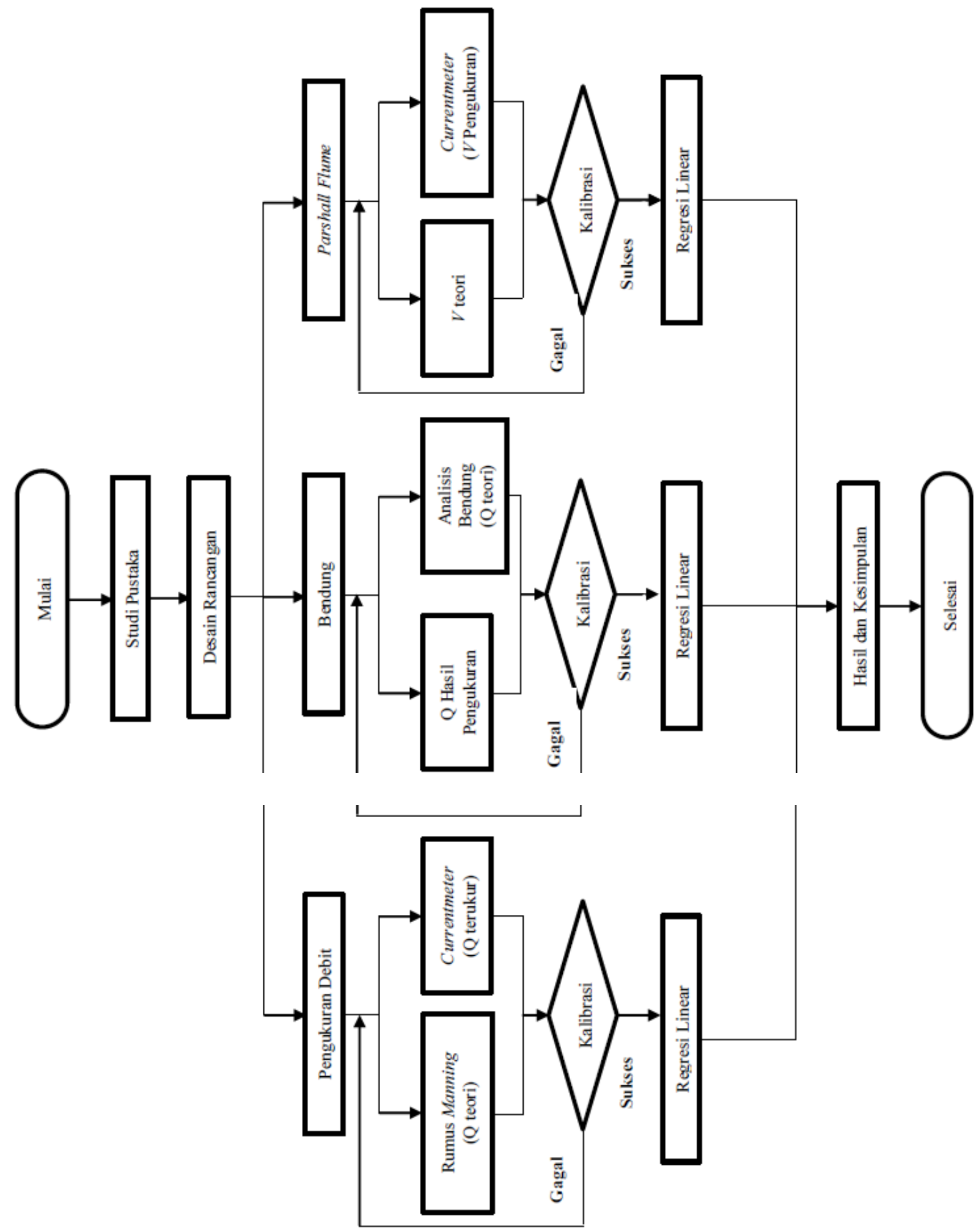




\section{REALISASI PROGRAM}

Anggaran Biaya

\begin{tabular}{|c|l|c|}
\hline No & \multicolumn{1}{|c|}{ Jenis Pengeluaran } & Biaya \\
\hline 1. & Peralatan penunjang & $\mathrm{Rp} 1.915 .000$ \\
\hline 2. & Bahan habis pakai & $\mathrm{Rp} 14.985 .000$ \\
\hline 3. & Lain-lain & $\mathrm{Rp} 2.500 .000$ \\
\hline & \multicolumn{2}{|c|}{ Total Anggaran } \\
\hline
\end{tabular}

\section{Jadwal Kegiatan}

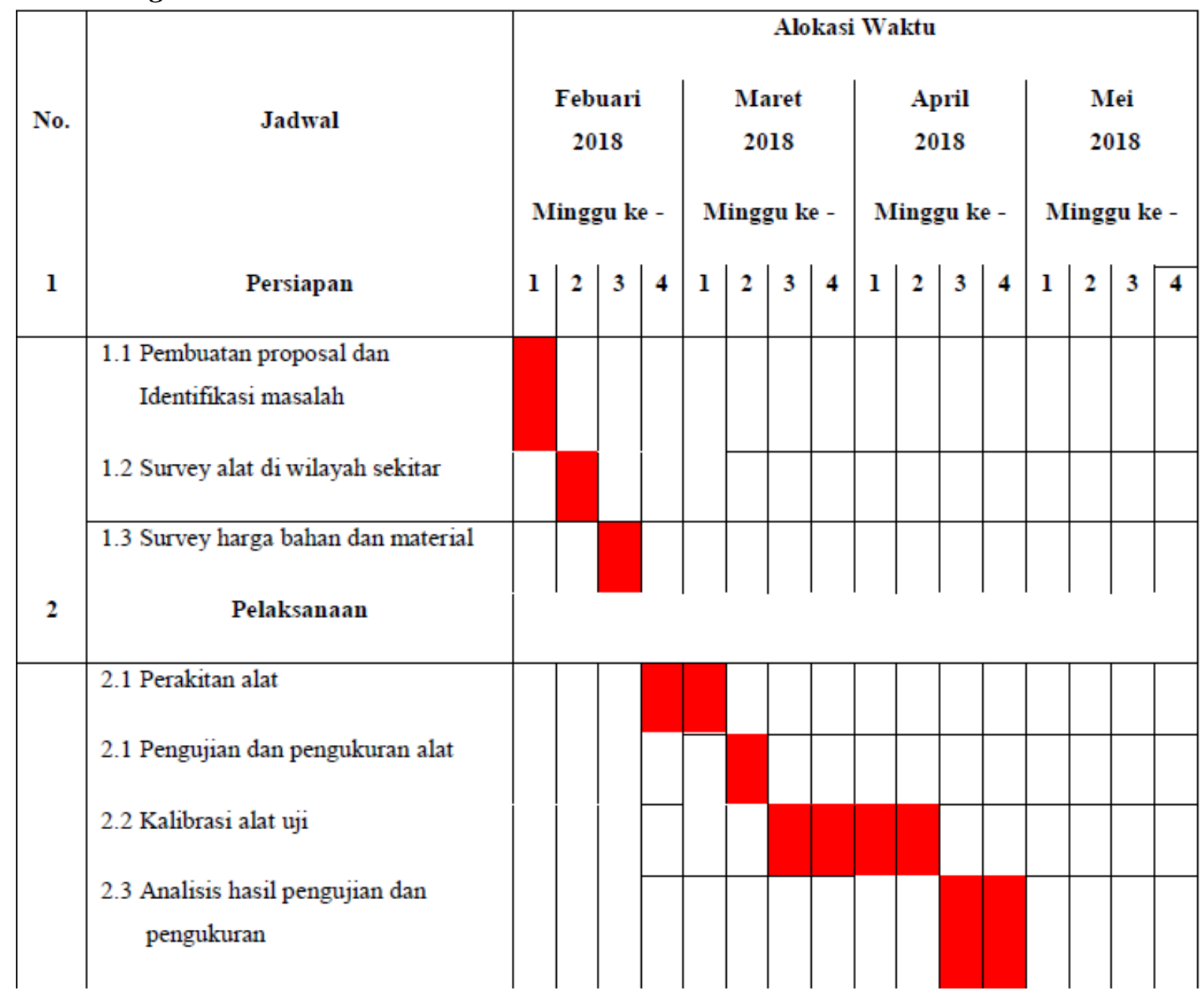




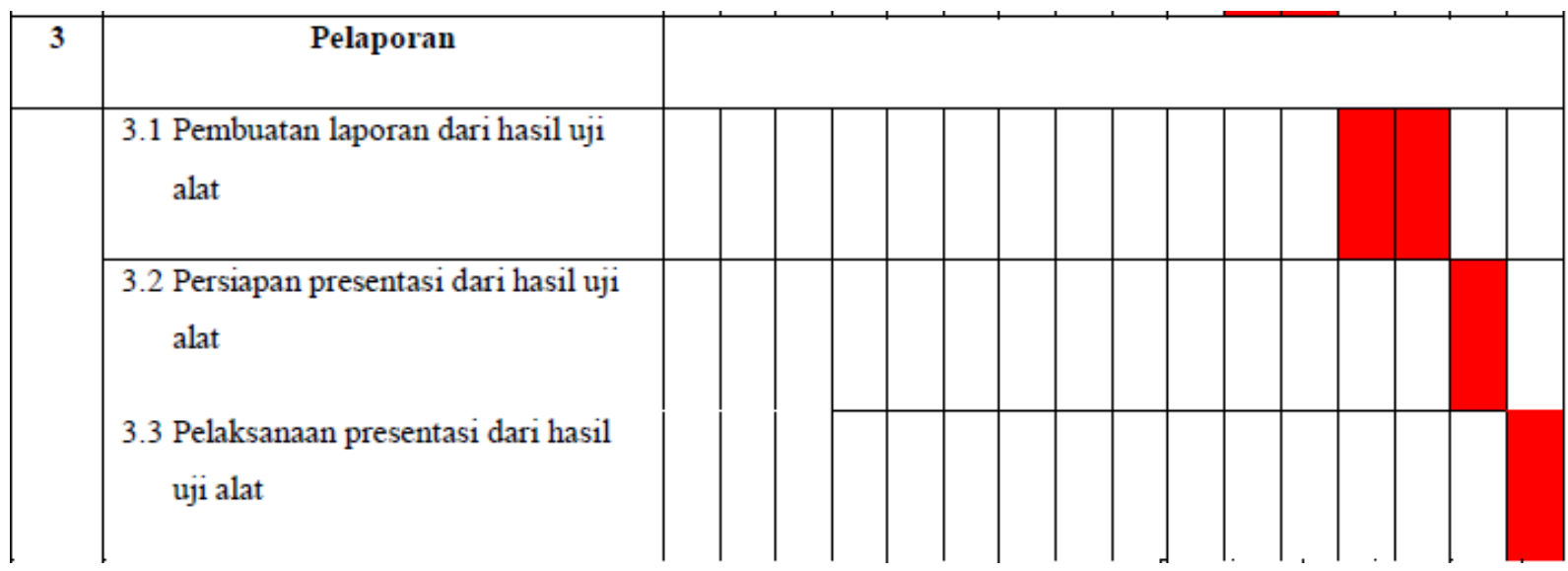

\section{REFERENSI}

Antariksa A, Berlandho N, Sihombing R, Utami Ade T, Sutendi A, dan Ambarini Wahyu T., 2010. Praktikum Mekanika Fluida: Pengaruh Kedalaman Aliran Terhadap Perilaku Gerusan Lokal Di Sekitar Gerusan Abutmen Jembatan, (https://id.scribd.com/doc/507076 71/ALIRAN-FLUIDAPADASALURAN-TERBUKA. Diakses 22 November 2017).

Aji S, T. Yanus, dan G. Martiani, 2014, Uji Kinerja Flume $10 \mathrm{CM}$ x 20 CM x 400 CM Melalui Pintu Air Sisi Tegak/Vertikal, Parshall Flume, Ambang Lebar Ujung Tumpul (Drempell) Dan Ambang Tajam/Tipis, Majalah Ilmiah UKRIM, Th. 2014, Edisi 1:19, Yogyakarta.

Chow Ven T, 1959. Hidrolika Saluran Terbuka, Terjemahan oleh E.V.
Nensi Rosalina, VFX. Kristanto Sugiharto, Suyatman, 1984, Penerbit Erlangga, Jakarta.

Klass. Y. S. K. Dua, 2010, Karakteristik Aliran Kritis Pada Pintu Sorong, dinamika TEKNIK SIPIL, Thn 2010, Vol. 10/No. 1, Politeknik Negeri Kupang, Kupang.

Purwati E, 2010, Model Alat Ukur Debit Saluran Irigasi Dengan Modifikasi Parshall Flume dan Drempell, Disertasi, (Tidak Diterbitkan), Universitas Brawijaya, Malang.

Sartono, 2014, Analisis Aliran Koefisien Debit Model Bendung Pada Laboratorium Hidrolika Teknik Sipil Uika Bogor, Skripsi, (Tidak Diterbitkan), Universitas IBN Khaldun, Bogor. 